\title{
Comparisons among Single-Word Tests for Korean Speech Sounds and Results of Assessment for Children with Speech Sound Disorders
}

\author{
Roo-Dah Yia , Soo-Jin Kim ${ }^{\mathrm{b}}$ \\ ${ }^{a}$ Bambini Development Center, Hwaseong, Korea \\ ${ }^{b}$ Department of Communication Disorders, Korea Nazarene University, Cheonan, Korea
}

Correspondence: Soo-Jin Kim, $\mathrm{PhD}$ Department of Communication Disorders, Korea Nazarene University, 48 Wolbong-ro, Seobuk-gu, Cheonan 31172, Korea

Tel: $+82-41-570-7978$

Fax: $+82-41-570-7846$

E-mail: sjkim@kornu.ac.kr

Received: October 5, 2019

Revised: November 4, 2019

Accepted: November 4, 2019

\begin{abstract}
Objectives: This study provides readers with information about the stimulus words of 4 Korean standardized tests for speech sound production and compares test results of children with speech sound disorders through the 4 tests. Methods: In Experiment 1, 4 tests were conducted on 15 children who have speech sound disorders. The test results were compared in terms of percentage of consonants correct (PCC) and standard deviation score. In Experiment 2, the stimulus words of the 4 tests were compared in terms of complexity and the number of opportunities for production of consonants Children's phonetic inventories were also compared. Results: In Exoperiment 1, there were significant correlations among the PCC of whole words in the 4 tests and the PCC of target phonemes in the 4 tests. However, the range of standard deviation in which children were included, and phonetic inventories varied with each test. In Experiment 2, the 4 tests provided different numbers of opportunities for production of consonants across each word position. None of the tests provided more than two opportunities for the production of each consonant. The tests varied in terms of phonological mean length of utterance (PMLU) of words that elicited the production of each of the consonants, and this led to differences in children's phonetic inventories. Conclusion: The results of this study provide clinicians with information that can assist them in selecting the ideal test for their clients. This study showed that there are limitations that exist in the current standardized tests for completing phonetic inventories. Clinicians will need to understand these limitations and conduct additional supplemental tests to compensate for the shortcomings.
\end{abstract}

Keywords: Speech sound disorder, Standardized test, Stimulus word, Phonetic inventory 말소리장애(speech sound disorders, SSD) 아동을 진단하기 위 해서는 말소리를 수집하고 분석해야 한다. 표준화된 말소리검사는 말소리 수집방법의 일환으로, 임상가들이 가장 널리 사용하는 방 법이다(McLeod \& Baker, 2014; Skahan, Watson, \& Lof, 2007). 표 준화된 검사를 시행하는 주된 목적 중 하나는 중재의 필요성을 확 인하는 것이다(Khan, 2002). 표준화된 검사는 또래 아동 규준과 비 교를 통해 SSD 아동을 구분하는 데 유용하다. 자음정확도(percentage of consonants correct, PCC)는 말소리 산출 능력을 평가할 때 가장 빈번하게 사용되는 측정치이다(Kim SJ, 2006). 표준화된
검사를 통해 아동의 말소리를 평가할 때 역시 PCC를 산출하며, 이 양적 측정치는 규준 비교에 사용된다. 일반적으로 $\mathrm{SSD}$ 를 진단하는 기준은 표준화된 검사 결과 $-1.5 \mathrm{SD}$ 이하이면서 자발화 문맥에서 연령에 비해 명료도에 문제가 있는 경우이며(Kim \& Shin, 2015), 표 준화된 검사에서 -1 SD 이하에 속하는 경우 중재가 필요한 것으로 판단하기도 한다(Bernthal, Bankson, \& Flipsen, 2017).

표준화된 검사를 실시하는 또 다른 목적은 아동의 말산출에서 오류가 있는 소리를 확인하고(McLeod \& Baker, 2014), 음운분석을 위한 샘플을 얻는 것이다(Eisenberg \& Hitchcock, 2010; Elbert \& 
Gierut, 1986; Kirk \& Vigeland, 2015; Macrae, 2017). 음운분석은 크게 독립분석과 관계분석으로 분류되는데, 독립분석의 한 종류 인 목록분석과 관계분석의 일부인 음운변동분석은 임상가들에 의해 가장 빈번하게 사용되는 절차이다(Skahan et al., 2007). 음운 변동분석이 더 발달된 말소리 체계를 지닌 아동들에게 적합한 데 반해(Bankson, Bernthal, \& Flipsen, 2013), 목록분석은 미성숙한 말소리 체계를 지닌 어린 아동에게 더 적합할 수 있다(Stoel-Gammon, 1987). 말소리목록은 아동이 산출하는 소리와 산출하지 못 하는 소리 모두를 식별하기 위해 사용되며, 아동이 자발적으로 산 출한 소리를 바탕으로 구성된다(Eisenberg \& Hitchcock, 2010). 말 소리목록은 치료 목표를 선정하기 위한 근거로 사용되는데(Eisenberg \& Hitchcock, 2010), 만약 평가 과정에서 수집된 샘플이 아동 의 말소리목록을 대표하지 못하면 필요한 목표들이 중재에 반영되 지 않을 수도 있다(Miccio, 2002).

표준화된 검사에서 샘플을 얻는 방법은 단어 산출을 유도하는 것이다. 표준화된 말소리검사들은 각기 다른 단어들을 자극으로 제시한다. 이러한 단어의 차이는 각 검사들이 독자적인 음운분석 을 고려한다는 것을 의미한다(Macrae, 2017). 자극단어들은 연구 자들에 의해 통제되었기 때문에 비교적 짧은 시간 내에 여러 단어 위치에 걸친 모든 목표음소를 평가할 기회를 제공하는데, 이는 한 낱말검사의 가장 큰 장점이 될 수 있지만, 모든 목표음소의 평가가 모든 음성적 환경을 고려한 음소의 평가로 이어지지는 않는다(Olsen, 2010). 또한 포괄적인 음운분석을 위해서는 각 단어 위치 내 개 별 자음 산출을 위한 기회를 최소 2회를 갖는 것이 바람직한데(Ingram \& Ingram, 2001; Stoel-Gammon, 1987), 특히 이 2회의 산출 은 한 소리가 아동의 말소리목록에 있다고 확정 짓기 위한 일반적 인 기준으로 여겨진다(Powell \& Miccio, 1996; Stoel-Gammon, 1985). Macrae (2017)는 영어권 국가에서 사용되는 말소리 검사도 구 12 개의 자극단어에 포함된 자음 산출 기회를 비교하였는데, 검 사마다 음소별 산출 기회수에서 차이가 있는 것으로 나타났으며, 대부분의 검사들이 각 단어 위치 내 대다수의 자음을 산출하는 데 단 한 번의 기회만을 포함하였다.

단어의 구조적 복잡성은 어린 아동의 산출 지속성과 정확성에 영향을 미치는 것으로 알려졌는데, 더 복잡한 단어는 덜 복잡한 단 어에 비해 덜 지속적이고 덜 정확하게 산출된다(Macrae, 2013; Mc-

Leod \& Hewett, 2008; Sosa \& Stoel-Gammon, 2012). Eisenberg와 Hitchcock (2010)은 음운론적 복잡성의 차이가 소리 산출에 영향 을 미칠 수 있다는 것을 근거로, 아동의 음성목록 구성을 위한 평가 과정에서 단순한 구조의 단어를 사용할 것을 제안하였다. 저자들 은 다음절 단어가 아닌 1 음절 단어에서, 또는 2 음절 단어의 강세 음
절에서 자음 산출 기회를 제공해야 한다고 주장하였다. 하지만 음 절수만으로는 단어의 복잡성을 측정할 수 없는데, 음절구조가 단 어의 복잡성에 영향을 미칠 수 있기 때문이다. Ingram (2002)은 전 체 단어 단위의 복잡성을 측정하는 데 있어 비교적 사용이 쉽고 신 뢰도가 높은 측정치로 평균음운길이(phonological mean length of utterance, PMLU)를 제안하였다. PMLU는 산출하고자 하는 단어 의 분절음수와 정확하게 산출한 자음수로 산출하는데, 사용하는 단어의 음운구조가 복잡해지고 길이가 길어지면 분절음의 수가 증 가하며, 이를 통해 단어의 복잡성이 지표에 반영된다(Kim \& Shin, 2015). PMLU를 산출하면 음절수만으로는 드러나지 않는 종성자 음의 유무가 반영되므로 단어의 복잡성을 수치화하여 볼 수 있다.

말소리목록을 구성할 때, 자음군은 목표음소의 산출 문맥으로 적절하지 않다(Eisenberg \& Hitchcock, 2010). 한국어는 자음군이 존재하지 않지만, 두 개 자음의 연쇄가 음절의 경계로 발생하는데 (Kim, 2010), 총 86가지 경우의 수로 어중종성과 어중초성의 결합 이 발음될 수 있다(Shin, 2008). Lee, Han과 Shim (2004)은 조음복 잡성이 비유창성과 조음오류에 미치는 영향을 살펴본 연구에서 2 음절 이상의 어절에서 각 음절의 모음 사이에 자음이 연속하여 나 타날 경우가 그렇지 않은 경우보다 더 복잡한 것으로 간주하였다. 또한 한국어 음운오류패턴 중 어중종성의 생략과 동화로 인한 대 치를 나타내는 '어중단순화'는 2-6세 아동의 음운변동을 연구한 $\operatorname{Kim~MJ~(2006)ㅇㅔㅅㅓ~'ㅈㅓㄴㅊㅔㄷㅏㄴㅇㅓㅂㅕㄴㄷㅗㅇ'~ㅈㅜㅇ~ㄱㅏㅈㅏㅇ~ㅁㅏㄶㅇㅡㄴ~ㅂㅣㅈㅜㅇㅇㅡㄹ~ㅊㅏㅈㅣㅎㅏㄴㅡㄴ~}$ 오류로 보고되었으며(Kim, 2010), 어중초성 탈락과 어중종성 탈락 은 일반적인 음운발달에서 나타날 수 있는 발달적 음운패턴에 해 당한다(Kim, 2014). 따라서 영어의 자음군과 마찬가지로 한국어에 서도 자음이 연쇄되는 환경은 그렇지 않은 환경보다 음성적으로 더 복잡하다고 할 수 있다. 그러므로 음운변동을 확인하고 싶다면 어중에 자음이 연쇄되는 조건이 유리하고, 어중초성에 목표자음 이 존재하는지 목록분석을 하고 싶다면 모음 뒤에 바로 초성이 오 는 환경이 적절할 것이다.

현재 국내에서 출판되어 사용되고 있는 표준화된 말소리 검사도 구로는 우리말 조음·음운평가(Urimal-Test of Articulation and Phonology, U-TAP; Kim \& Shin, 2004), 아동용 발음평가(Assessment of Phonology and Articulation for Children, APAC; Kim, Pae, \& Park, 2007), 한국어 표준 그림 조음음운검사(Korean Standard Picture of Articulation and Phonological Test, KS-PAPT; Seok, Park, Shin, \& Park, 2008)가 있다. 이 중 UTAP은 현재 개정 작 업 중에 있으며, 개정판 우리말 조음·음운평가2 (Urimal Test of Articulation and Phonology 2nd edition, UTAP2; Kim, Ha, Kim, \& Shin, in press)로 출판될 예정이다. 국내의 표준화된 말소리 검사는 
모두 말소리목록 검사이며 음운변동분석을 위한 틀을 제공한다.

네 검사는 평가를 위해 각기 다른 단어들을 사용하지만, 자극으 로 제시되는 단어들의 특성에 관한 정보 및 음운분석의 수행을 위 한 기회수와 관련된 정보는 아직까지 제공된 바가 없다. 또한 임상 현장에서 말소리검사는 SSD 아동 또는 의심 아동을 대상으로 실 시한다. 그러나 검사도구의 개발 과정에서 표집에 포함된 아동은 대부분 일반발달 아동이며, 공인타당도 검증을 위해 다른 검사 결 과와의 상관을 분석하기도 하나, 대부분의 연구는 일반발달 아동 을 대상으로 실시되었다. SSD 아동은 생활연령과 관계없이 일반발 달 아동들과 다른 발달 양상을 보일 수 있으나, SSD 아동을 대상으 로 실시한 검사 결과를 비교한 연구는 부족한 것이 실정이다. Park 과 Shin (2003)은 국내 말소리 검사가SSD 아동의 음운변동에 어떤 영향을 미치는지 살펴보기 위해 그림자음검사와 한국 표준 그림 조음검사의 결과를 비교하였는데(as cited in Park \& Shin, 2003), $\mathrm{SSD}$ 아동을 대상으로 장애 중증도에 따라 고도와 경도 음운장애 로 분류하였다. 그 결과 경도음운장애 아동 집단이 음운변동의 비 율과 순위 모두에서 많은 차이가 있는 것으로 나타나, 고도음운장 애 아동에 비해 경도음운장애 아동이 음운환경 및 운율적 위치의 영향을 많이 받는다고 결론지었으나, 대상 아동은 경도음운장애 아동 3 명, 고도음운장애 아동 1 명으로 총 4 명에 불과하였다. 또한 연구에 사용된 그림자음검사는 현재의 UTAP으로 재출판되었으 나, 새로운 검사들이 출판되기 이전에 수행된 연구이다.

본 연구에서는 국내 표준화된 말소리 검사를 SSD 아동들에게 실시한 결과를 비교하고, 네 검사에 포함된 자극단어를 비교하여 어떤 차이가 있는지 살펴보았다. 구체적으로 연구1에서는 SSD 아 동들에게 네 검사를 모두 실시한 결과 전체 단어의 PCC와 규준 비 교를 위한 목표음소의 PCC에 차이가 있는지, 대상 아동이 속한 규 준 구간에 차이가 있는지 살펴보았으며, 연구2에서는 네 검사가 자 극으로 제시하는 단어의 자음 산출 기회수에 차이가 있는지, 자극 단어의 복잡성에 차이가 있는지, 단어의 복잡성에 따라 $\mathrm{SSD}$ 아동 의 말소리목록에 어떠한 차이가 있는지 살펴보았다.

\section{연구방법}

\section{연구1}

\section{연구 대상}

연구에 참여한 대상자는 말소리장애로 진단받고 경기 및 제주 지역의 사설 기관에서 치료를 받고 있는 아동 15 명이다. 아동별 정 보는 Appendix 1에 제시하였다. 대상 아동 연령 범위는 3세 3개월-6 세 5 개월로, 평균 연령은 4 세 8 개월이며, 남녀 비율은 3:2이다.

\section{도구 및 전사}

모든 대상 아동에게 연구 1 에서 분석한 네 개의 검사를 무선적으 로 실시하였다. 한 아동의 경우 2 개 검사 실시 후 검사를 거부하여 일주일 뒤 나머지 검사를 실시하였다. 나머지 14 명의 아동은 한 세 션 내에서 4 개 검사를 연속으로 실시하였다. 모든 검사는 독립된 공 간에서 진행되었으며, 일대일 상황에서 평가하고 녹음되었다. 검사 상황에서 수집된 아동의 발화 자료는 연구자가 간략 음성전사를 실시하고 다음 분석을 실시하였다.

\section{자음정확도}

전사된 자료를 기초로 검사도구별 대상 아동의 자음정확도(PCC) 를 산출하였다. 대상 아동의 말산출에서 나타난 대치, 생략, 왜곡 오 류를 오조음으로 보고 PCC 산출에 반영하였다. PCC는 total PCC 와 target PCC로 구분하였는데, total PCC에는 전체 자극단어에 포함된 모든 자음이 포함되었고, target PCC에는 검사별로 점수화 및 말소리목록 구성을 위해 설계된 목표음소만이 포함되었다.

\section{규준 구간}

검사도구에 따라 대상 아동이 속한 Z점수 표준편차 구간에 차이 가 있는지 살펴보았다. UTAP2는 아직 출판되지 않았으나, 저자의 허락을 구하여 $\mathrm{Ha}, \mathrm{Kim}, \mathrm{Kim}$ 과 Shin (2019)의 연구로부터 얻어 진 규준 자료를 적용하였다.

\section{전사신뢰도}

본 연구에 쓰인 전체 자료의 $20 \%$ 를 무작위로 선정하여 2 급 언어 재활사 2 명이 연구자와 동일한 기준으로 전사한 후, 전체 목표자음 을 검사자 간 일치한 자음으로 나눈 비율로 검사자 간 신뢰도를 살 펴보았다. 그 결과, 검사자 간 신뢰도는 $95.9 \%$ 였다.

\section{연구2}

각 검사도구의 단어 검사에 포함된 자극단어들에 대해 포괄적인 분석을 시행하였다. 분석에는 UTAP의 단어 30 개, $\mathrm{APAC}$ 의 단어 37 개, KS-PAPT의 선별검사 단어 30 개, UTAP2의 단어 30 개가 포 함되었다.

\section{자음 산출 기회}

검사도구별 자극단어에 포함된 자음의 산출 기회수를 단어 내 어두초성, 어중초성, 어중종성, 어말종성 위치로 나누어 살펴보았 다. 점수화를 위한 목표음소뿐 아니라 단어에 포함된 모든 자음이 분석에 포함되었다. 
복잡성

자극단어의 음절수에는 반영되지 않는 음운구조의 복잡성과 분 절음수 증가에 따른 복잡성을 측정하는 지표로 PMLU를 사용하 였다. 자극단어의 PMLU는 각 검사도구가 제시하는 목표발음 형태 를 기준으로 산출하였다. PMLU 산출 기준은 Yoon, Kim과 Kim (2013)을 참고하였다. 이중모음은 첫 음절이 아닌 곳에서 단모음화 되는 경향이 있으나, 자극단어가 이중모음을 포함하는 경우 계산 기준에 따라 이중모음에 1점을 추가하였다. 먼저 검사도구별 전체 자극단어의 평균 $\mathrm{PMLU}$ 를 비교하였으며, 목표음소별로 산출이 유 도된 자극단어의 복잡성 정도 역시 PMLU 지표를 사용해 비교하 였다. 목표음소는 단어 내 위치에 따라 어두초성, 어중초성, 어중종 성, 어말종성으로 분류하였다.

\section{말소리목록}

연구1에서 얻은 자료를 바탕으로 검사도구에 따라 대상 아동들 의 말소리목록에 어떠한 차이가 있는지 살펴보았다. 말소리목록 구 성을 위해 통제된 목표음소를 산출하지 못한 경우 해당 음소가 대 상 아동의 말소리목록에 존재하지 않는 것으로 간주하였다. 2 개 이 상의 단어에서 목표음소의 산출 기회가 제공된 경우 Powell과 Mic-

Table 1. Total PCC and target PCC of each test

\begin{tabular}{lccc}
\hline & $N$ & Total PCC & Target PCC \\
\hline U-TAP & 15 & $67.28 \pm 17.96(34.48-95.40)$ & $69.92 \pm 18.30(30.23-93.02)$ \\
APAC & 15 & $67.29 \pm 17.00(37.50-89.58)$ & $68.86 \pm 16.76(37.14-90.00)$ \\
KS-PAPT & 15 & $65.68 \pm 18.88(27.27-88.64)$ & $66.13 \pm 19.38(28.00-90.00)$ \\
UTAP2 & 15 & $67.38 \pm 17.30(38.30-87.23)$ & $69.44 \pm 17.69(35.42-89.58)$ \\
\hline
\end{tabular}

Values are presented as mean $\pm \mathrm{SD}$ (range).

$\mathrm{PCC}=$ percentage of consonants correct; Total $\mathrm{PCC}=\mathrm{PCC}$ of whole words; Target $\mathrm{PCC}=\mathrm{PCC}$ of target phonemes for scoring; UTAP = Urimal-Test of Articulation and Phonology (Kim \& Shin, 2004); APAC=Assessment of Phonology and Articulation for Children (Kim, Pae, \& Park, 2007); KS-PAPT = Korean Standard Picture of Articulation and Phonological Test (Seok, Park, Shin, \& Park, 2008); UTAP2=Urimal-Test of Articulation and Phonology 2nd edition (Kim, Ha, Kim, \& Shin, in press). cio (1996)와 Stoel-Gammon (1985)에 따라 2회 이상의 올바른 소 리 산출을 근거로 대상 아동의 말소리목록을 구성하였다. 작성된 말소리목록을 바탕으로 단어 내 위치별 말소리목록에서 각각의 음 소를 갖고 있지 않은 아동의 수를 살펴보았다.

\section{연구결과}

\section{연구1}

\section{자음정확도}

검사도구별 total PCC, target PCC의 평균과 표준편차, 범위는 Table 1과 같다. 네 검사의 평균 total PCC는 65.68\%-67.38\%로 유사 한 수치를 보였으며, UTAP2가 가장 높고 KS-PAPT가 가장 낮았다. 평균 target PCC는 66.13\%-69.44\%로 역시 유사한 수치를 보였다.

네 검사의 PCC 간 Pearson 상관계수는 Table 2와 같다. 네 검사 의 total PCC 간 상관은 .966 이상, target PCC 간 상관은 .883 이상 으로 높게 나타났다.

\section{규준 구간}

네 검사별로 각 규준 구간에 속한 아동의 수는 Table 3과 같다. 각 대상 아동들이 검사별로 속한 규준 구간은 Appendix 1에 제시

Table 3. Number of children included in z-score section

\begin{tabular}{lcccc}
\hline & $<-2$ SD & -2 SD to -1.5 SD & -1.5 SD to -1 SD & -1 SD to 0 SD \\
\hline UTAP & 13 & 1 & 1 & 0 \\
APAC & 10 & 3 & 1 & 1 \\
KS-PAPT & 15 & 0 & 0 & 0 \\
UTAP2 & 9 & 3 & 2 & 1 \\
\hline
\end{tabular}

UTAP = Urimal-Test of Articulation and Phonology (Kim \& Shin, 2004); APAC=Assessment of Phonology and Articulation for Children (Kim, Pae, \& Park, 2007); KS-PAPT = Korean Standard Picture of Articulation and Phonological Test (Seok, Park, Shin, \& Park, 2008); UTAP2 = Urimal-Test of Articulation and Phonology 2nd edition (Kim, Ha, Kim, $\&$ Shin, in press).

Table 2. Result of correlational analysis among PCC of 4 tests

\begin{tabular}{|c|c|c|c|c|c|c|c|c|}
\hline & \multicolumn{4}{|c|}{ Total PCC } & \multicolumn{4}{|c|}{ Target PCC } \\
\hline & UTAP & APAC & KS-PAPT & UTAP2 & UTAP & APAC & KS-PAPT & UTAP2 \\
\hline UTAP & 1 & & & & 1 & & & \\
\hline APAC & $.984^{* *}$ & 1 & & & $.928^{* *}$ & 1 & & \\
\hline KS-PAPT & $.966^{* *}$ & $.972^{* *}$ & 1 & & $.883^{* *}$ & $.944^{* *}$ & 1 & \\
\hline UTAP2 & $.980^{* *}$ & $.982^{* *}$ & $.975^{* *}$ & 1 & $.923^{* *}$ & $.943^{* *}$ & $.942^{* *}$ & 1 \\
\hline
\end{tabular}

$\mathrm{PCC}=$ percentage of consonants correct; Total PCC = PCC of whole words; Target PCC = PCC of target phonemes for scoring; UTAP=Urimal-Test of Articulation and Phonology (Kim \& Shin, 2004); APAC= Assessment of Phonology and Articulation for Children (Kim, Pae, \& Park, 2007); KS-PAPT= Korean Standard Picture of Articulation and Phonological Test (Seok, Park, Shin, \& Park, 2008); UTAP2=Urimal-Test of Articulation and Phonology 2nd edition (Kim, Ha, Kim, \& Shin, in press). ${ }^{* *} p<.01$. 
하였다. SSD 아동 15 명 가운데 APAC에서 5 세 1 개월 남아 1 명과 $\mathrm{UTAP} 2$ 에서 3 세 9 개월 남아 1 명이 일반적인 장애판정 구간이 아닌 $-1 \mathrm{SD}-0 \mathrm{SD}$ 에 속하는 것으로 나타났다.

\section{연구2}

\section{자음 산출 기회}

검사도구별 자극단어에 포함된 초성 자음 산출 기회수는 Table 4 와 같다. 어두초성 위치에서 모든 검사도구는 각기 다른 7 개의 음 소에서 2 회 이상의 기회를 제공하였다. APAC은 어두초성 /리의 산출 기회를 제공하지 않았다. 어중초성 위치에서는 UTAP이 7개, $\mathrm{APAC}$ 이 8개, KS-PAPT가 9 개, UTAP2가 10개의 각기 다른 음소에 서 2 회 이상의 기회를 제공하였다. APAC과 UTAP2는 어중초성 /히의 산출 기회를 제공하지 않았다. 전체 초성 자음의 산출 기회 는 가장 많은 단어수를 자극으로 제시하는 APAC이 65회로 가장
많았으며, 그 다음으로 UTAP2, KS-PAPT, UTAP이 각각 63회, 62 회, 60 회의 기회를 제공하였다. 치경마찰음은 $\mathrm{APAC}$ 이 11 회로 가 장 많은 기회를 제공한 반면 UTAP2는 6회의 기회를 제공하였고, 연구개폐쇄음은 UTAP2가 14회로 가장 많은 기회를 제공한 반면 $\mathrm{UTAP}$ 은 11 회의 기회를 제공하였다. 경구개파찰음은 UTAP2가 13 회로 가장 많은 기회를 제공한 반면 UTAP과 APAC은 각 9 회의 기 회를 제공하였고, 유음은 UTAP이 7회로 가장 많은 기회를 제공한 반면 KS-PAPT는 4 회의 기회를 제공하였다.

검사도구별 자극단어에 포함된 종성 자음 산출 기회수는 Table 5 와 같다. 어중종성 위치에서 2 회 이상의 산출 기회가 유도된 자음 은 UTAP이 4 개, APAC이 5개, KS-PAPT가 5개, UTAP2가 3개였 다. UTAP은/ㅂ, ㄷ, 리의 산출 기회를 제공하지 않았으며, APAC 과 UTAP2는 /디의 산출 기회를 제공하지 않았고, KS-PAPT는 모 든 자음의 산출 기회를 제공하였다. 어말종성 위치에서는 네 검사

Table 4. Number of opportunities for production for each WISI and WMSI consonant in each test

\begin{tabular}{|c|c|c|c|c|c|c|c|c|c|c|c|c|c|c|c|c|c|c|c|}
\hline & $\forall$ & 빠 & 표 & ᄃ & ᄄᄄ & $E$ & $\neg$ & 77 & F & $\curlywedge$ & $\mu$ & ᄒ & ス & मा & ᄎ & $\square$ & ᄂ & ᄅ & Total \\
\hline \multicolumn{20}{|l|}{ WISI } \\
\hline UTAP & 1 & 1 & 1 & 2 & 1 & 1 & 5 & 1 & 1 & 2 & 1 & 1 & 2 & 1 & 2 & 2 & 2 & 1 & 28 \\
\hline APAC & 4 & 1 & 1 & 1 & 1 & 1 & 3 & 1 & 1 & 3 & 1 & 3 & 1 & 1 & 2 & 2 & 2 & 0 & 29 \\
\hline KS-PAPT & 4 & 1 & 2 & 1 & 1 & 2 & 2 & 1 & 2 & 2 & 1 & 1 & 3 & 1 & 1 & 1 & 1 & 1 & 28 \\
\hline UTAP2 & 1 & 1 & 2 & 1 & 1 & 1 & 6 & 1 & 1 & 1 & 1 & 2 & 2 & 2 & 1 & 1 & 2 & 2 & 29 \\
\hline \multicolumn{20}{|l|}{ WMSI } \\
\hline UTAP & 2 & 1 & 1 & 1 & 1 & 1 & 1 & 2 & 1 & 2 & 2 & 1 & 1 & 1 & 2 & 5 & 1 & 6 & 32 \\
\hline APAC & 2 & 1 & 1 & 2 & 1 & 1 & 6 & 1 & 1 & 4 & 3 & 0 & 3 & 1 & 1 & 2 & 1 & 5 & 36 \\
\hline KS-PAPT & 2 & 1 & 1 & 1 & 1 & 1 & 4 & 2 & 2 & 1 & 3 & 1 & 4 & 2 & 1 & 3 & 1 & 3 & 34 \\
\hline UTAP2 & 3 & 1 & 1 & 1 & 1 & 1 & 3 & 2 & 1 & 2 & 2 & 0 & 3 & 2 & 3 & 3 & 1 & 4 & 34 \\
\hline
\end{tabular}

WISI = word-initial syllable-initial; WMSI = word-medial syllable-initial; UTAP=Urimal-Test of Articulation and Phonology (Kim \& Shin, 2004); APAC=Assessment of Phonology and Articulation for Children (Kim, Pae, \& Park, 2007); KS-PAPT = Korean Standard Picture of Articulation and Phonological Test (Seok, Park, Shin, \& Park, 2008); UTAP2= Urimal-Test of Articulation and Phonology 2nd edition (Kim, Ha, Kim, \& Shin, in press).

Table 5. Number of opportunities for production for each WMSF and WFSF consonant in each test

\begin{tabular}{|c|c|c|c|c|c|c|c|c|}
\hline & $\forall$ & $\sqsubset$ & $\neg$ & $\square$ & ᄂ & 0 & ᄅ & Total \\
\hline \multicolumn{9}{|l|}{ WMSF } \\
\hline UTAP & 0 & 0 & 2 & 2 & 4 & 5 & 0 & 13 \\
\hline APAC & 1 & 0 & 2 & 2 & 3 & 6 & 3 & 17 \\
\hline KS-PAPT & 1 & 1 & 2 & 2 & 2 & 2 & 4 & 14 \\
\hline UTAP2 & 1 & 0 & 4 & 1 & 3 & 6 & 1 & 16 \\
\hline \multicolumn{9}{|l|}{ WFSF } \\
\hline UTAP & 1 & 2 & 1 & 2 & 2 & 4 & 2 & 14 \\
\hline APAC & 2 & 2 & 1 & 2 & 2 & 2 & 3 & 14 \\
\hline KS-PAPT & 2 & 1 & 3 & 1 & 2 & 1 & 2 & 12 \\
\hline UTAP2 & 1 & 2 & 2 & 2 & 3 & 4 & 1 & 15 \\
\hline
\end{tabular}

WMSF=word-medial syllable-final; WFSF=word-final syllable-final; UTAP=Urimal-Test of Articulation and Phonology (Kim \& Shin, 2004); APAC=Assessment of Phonology and Articulation for Children (Kim, Pae, \& Park, 2007); KS-PAPT = Korean Standard Picture of Articulation and Phonological Test (Seok, Park, Shin, \& Park, 2008); UTAP2=UrimalTest of Articulation and Phonology 2nd edition (Kim, Ha, Kim, \& Shin, in press). 

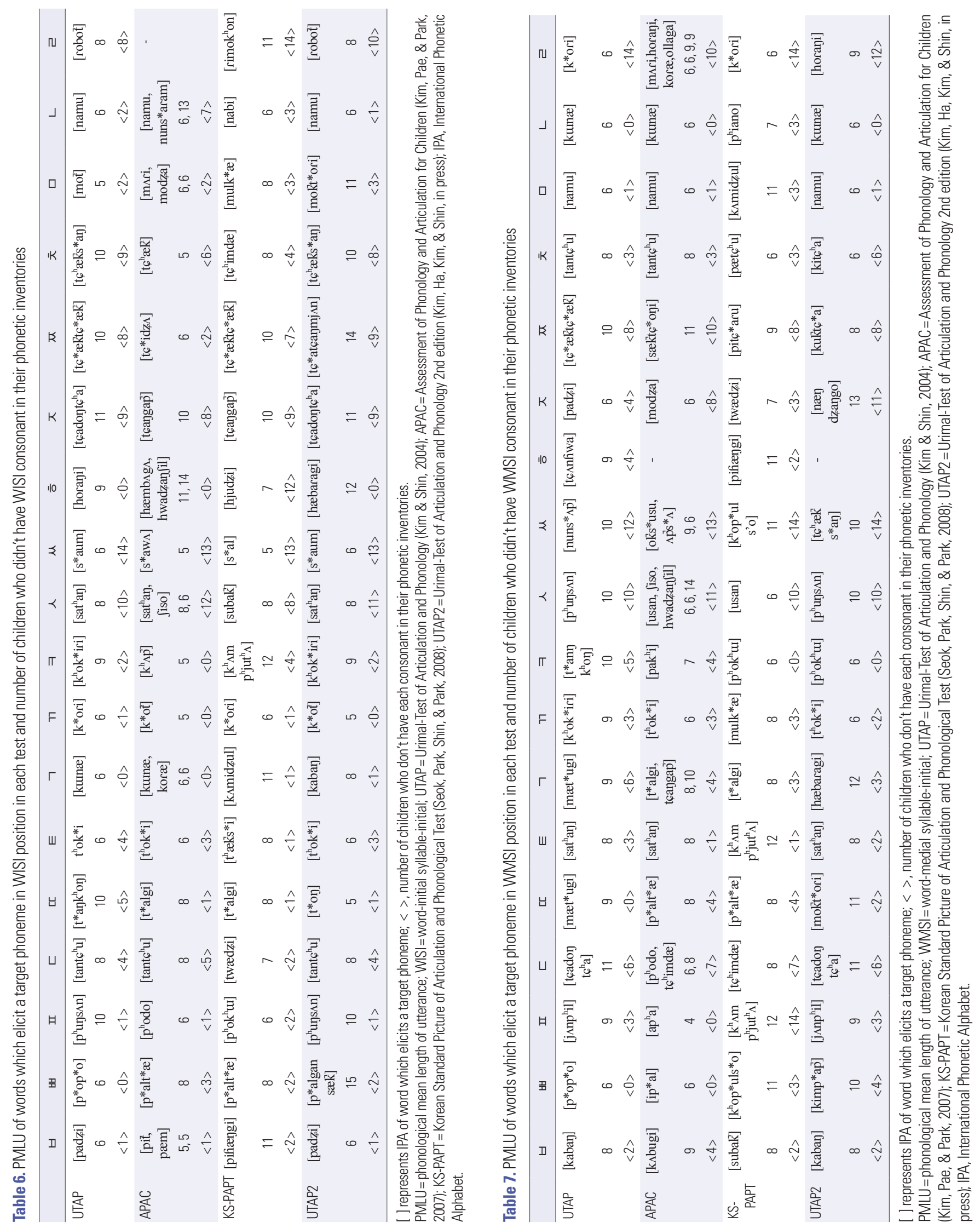
가 모든 자음에 대한 산출 기회를 제공하였는데, 2 회 이상의 기회가 유도된 자음은 UTAP이 5개, APAC이 6개, KS-PAPT가 4개, UTAP2 가 5 개였다. 전체 종성 자음의 산출 기회는 APAC과 UTAP2가 31 회로 가장 많았다. 음소별로 /ㅂ, ᄃ, ㅁ, ㄴ/는 네 검사가 유사한 기 회수를 제공한 반면, /ᄀ, O, 리의 산출 기회는 검사별로 최대 7 회 까지 차이를 보였다.

\section{복잡성}

전체 자극단어의 평균 $\mathrm{PMLU}$ 는 UTAP이 8.10, APAC이 7.46, KS-PAPT가 8.17, UTAP2가 8.57로 네 검사가 유사한 음운구조 복 잡성을 보였으며, UTAP2가 가장 높았고 APAC이 가장 낮았다. Tables 6-9는 산출이 유도된 자극단어의 목표발음 형태와 해당 단어 의 PMLU를 단어 내 위치에 따라 음소별로 제시한 것이다. 목표음 소의 산출이 2 회 이상 유도된 경우 해당 단어들의 PMLU를 각각

Table 8. PMLU of words which elicit a target phoneme in WMSF position in each test and number of children who didn't have WMSF consonant in their phonetic inventories

\begin{tabular}{|c|c|c|c|c|c|c|c|}
\hline & $\forall$ & $\sqsubset$ & $\neg$ & $\square$ & ᄂ & O & ᄅ \\
\hline \multirow[t]{3}{*}{ UTAP } & - & - & [tchæks*ay] & - & [tcınfiwa] & - & - \\
\hline & & & 10 & & 9 & & \\
\hline & & & $<10>$ & & $<3>$ & & \\
\hline \multirow[t]{3}{*}{ APAC } & {$\left[\Lambda \mathrm{ps}^{*} \Lambda\right]$} & - & [oks*usu] & 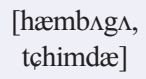 & $\begin{array}{c}\text { [tantchu, } \\
\text { nuns*aram] }\end{array}$ & $\begin{array}{l}\text { [jaymal, tçaygap̉ } \\
\text { hwadzayfil] }\end{array}$ & [ollaga] \\
\hline & 6 & & 9 & 11,8 & 8,13 & $9,10,14$ & 9 \\
\hline & $<8>$ & & $<11>$ & $<6>$ & $<10>$ & $<7>$ & $<4>$ \\
\hline \multirow[t]{3}{*}{ KS-PAPT } & {$\left[\mathrm{d} z \Lambda \overrightarrow{p s}^{*} *_{\mathrm{i}}\right]$} & [su‡k*arak] & [thæks*i] & [tçhimdæ] & [bandzi] & [tçaygap̉] & [khop*uls*o] \\
\hline & 8 & 13 & 8 & 8 & 8 & 10 & 11 \\
\hline & $<3>$ & $<13>$ & $<10>$ & $<6>$ & $<4>$ & $<4>$ & $<7>$ \\
\hline \multirow[t]{3}{*}{ UTAP2 } & {$\left[\mathrm{d} z \wedge \mathrm{ps}^{*} \mathrm{i}\right]$} & - & [kuktc*a] & [kimp*ap̉] & [tantchu] & [horani] & [p*algansæk] \\
\hline & 8 & & 8 & 10 & 8 & 9 & 15 \\
\hline & $<5>$ & & $<7>$ & $<5>$ & $<7>$ & $<5>$ & $<4>$ \\
\hline
\end{tabular}

[ ] represents IPA of word which elicits a target phoneme; $<>$, number of children who don't have each consonant in their phonetic inventories.

PMLU = phonological mean length of utterance; WMSF= word-medial syllable-final; UTAP=Urimal-Test of Articulation and Phonology (Kim \& Shin, 2004); APAC=Assessment of Phonology and Articulation for Children (Kim, Pae, \& Park, 2007); KS-PAPT = Korean Standard Picture of Articulation and Phonological Test (Seok, Park, Shin, \& Park, 2008); UTAP2 = Urimal-Test of Articulation and Phonology 2nd edition (Kim, Ha, Kim, \& Shin, in press); IPA, International Phonetic Alphabet.

Table 9. PMLU of words which elicit a target phoneme in WFSF position in each test and number of children who didn't have WFSF consonant in their phonetic inventories

\begin{tabular}{|c|c|c|c|c|c|c|c|}
\hline & $\forall$ & $\sqsubset$ & $\neg$ & $\square$ & ᄂ & O & ᄅ \\
\hline \multirow[t]{3}{*}{ UTAP } & {$\left[\right.$ nuns $\left.^{*} \Lambda \mathrm{p}^{\top}\right]$} & [moț] & - & [s*aum] & - & [kabay] & [j $\left.\wedge n p^{\mathrm{h}} \mathrm{il}\right]$ \\
\hline & 10 & 5 & & 6 & & 8 & 9 \\
\hline & $<6>$ & $<4>$ & & $<3>$ & & $<1>$ & $<4>$ \\
\hline \multirow[t]{3}{*}{ APAC } & {$\left[\mathrm{k}^{\mathrm{h}} \Lambda \mathrm{p}^{7}\right]$} & [pił̄, k*ỡ] & [tchæk] & [nuns*aram, pæm] & [usan, pjıฤwın] & [sat ${ }^{\mathrm{h}}$ ay, angj $\left.\Lambda \mathrm{y}\right]$ & [jaymal, ip*al] \\
\hline & 5 & 5,5 & 5 & 13,5 & 6,10 & 8,9 & 9,6 \\
\hline & $<2>$ & $<6>$ & $<3>$ & $<3>$ & $<8>$ & $<2>$ & $<1>$ \\
\hline \multirow[t]{3}{*}{ KS-PAPT } & {$\left[\mathrm{t}^{\mathrm{h}} \mathrm{op}\right]$} & [dzamot'] & [subak] & [kom] & [usan] & [angj $\Lambda \mathrm{y}]$ & {$[\mathrm{k} \wedge$ midzul $]$} \\
\hline & 5 & 8 & 8 & 5 & 6 & 9 & 11 \\
\hline & $<5>$ & $<5>$ & $<2>$ & $<3>$ & $<5>$ & $<1>$ & $<0>$ \\
\hline \multirow[t]{3}{*}{ UTAP2 } & [kimp*ap̉] & {$\left[\mathrm{k}^{*} \mathrm{ot}\right]$} & {$\left[\mathrm{t} \epsilon^{*} æ \mathrm{k} t \epsilon^{*} æ \mathrm{k}^{\top}\right]$} & [kom] & {$[\operatorname{ramj} \Lambda \mathrm{n}]$} & {$\left[\mathrm{t}^{*} \mathrm{on}\right]$} & [j $\left.\wedge n p^{\mathrm{h}} \mathrm{il}\right]$ \\
\hline & 10 & 5 & 10 & 5 & 9 & 5 & 9 \\
\hline & $<4>$ & $<3>$ & $<4>$ & $<3>$ & $<5>$ & $<0\rangle$ & $<4>$ \\
\hline
\end{tabular}

[ ] represents IPA of word which elicits a target phoneme; $<>$, number of children who don't have each consonant in their phonetic inventories.

$\mathrm{PMLU}=$ phonological mean length of utterance; WFSF= word-final syllable-final; UTAP=Urimal-Test of Articulation and Phonology (Kim \& Shin, 2004); APAC=Assessment of Phonology and Articulation for Children (Kim, Pae, \& Park, 2007); KS-PAPT = Korean Standard Picture of Articulation and Phonological Test (Seok, Park, Shin, \& Park, 2008); UTAP2 = Urimal-Test of Articulation and Phonology 2nd edition (Kim, Ha, Kim, \& Shin, in press); IPA, International Phonetic Alphabet. 
제시하였다. 검사도구에 따른 PMLU의 차이는 어두초성에서 최고 9 , 어중초성에서 최고 8 , 어중종성에서 최고 6 , 어말종성에서 최고 8 로 나타났다.

\section{말소리목록}

검사도구별로 표준화 점수에 기여하는 목표음소의 산출 가능 여부를 근거로 대상 아동 개개인의 말소리목록을 작성하였다. 단 어 내 위치에 따라 각 음소를 산출하지 못한 아동의 수를 Tables 6-9에 제시하였다.

단어 내 위치별로 아동 수의 차이가 가장 큰 음소들을 살펴보면, 어두초성 /ㅎ/는 KS-PAPT의 [휴지]에서 산출하지 못한 아동이 12 명으로 가장 많았고, UTAP의 [호랑이], $\mathrm{APAC}$ 의 [햄버거]와 [화장 실], UTAP2의 [해바라기]에서 산출하지 못한 아동이 각 0명으로 가장 적었다. 어중초성 /프/는 KS-PAPT의 [컴퓨터]에서 산출하지 못한 아동이 14 명으로 가장 많았고, $\mathrm{APAC}$ 의 [아파]에서 산출하지 못한 아동이 0 명으로 가장 적었다. 어중종성 /ㄴ/는 APAC의 [단 추]와 [눈싸람]에서 산출하지 못한 아동이 10 명으로 가장 많았고, $\mathrm{UTAP}$ 의 [전화]에서 산출하지 못한 아동이 3명으로 가장 적었다. 어말종성 /ㅂ/는 UTAP의 [눈썹]에서 산출하지 못한 아동이 6명으 로 가장 많았고, $\mathrm{APAC}$ 의 [컵]에서 산출하지 못한 아동이 2명으로 가장 적었다.

\section{논의 및 결론}

\section{규준 비교}

규준 비교에 사용되는 target PCC 간의 높은 상관에도 불구하 고, 실제 임상현장에서 치료를 받고 있는 대상 아동들이 속한 규준 구간은 검사에 따라 차이가 있었다. 특히 APAC과 UTAP2에서 각 5 세 1 개월과 3 세 9 개월 아동이 -1 SD-0 SD에 속하는 것으로 나타 났는데, 이러한 결과는 다른 검사를 시행할 경우 중재의 필요성을 권고를 받게 될 아동이 특정 검사를 시행할 경우 중재 필요성을 권 고 받지 못할 가능성이 있음을 시사한다.

그러나, 이러한 결과의 차이는 각 검사에 포함된 규준 자료의 차 이를 반영하는 것일 수 있다. 검사 결과에 가장 영향을 미쳤을 것으 로 예상되는 변수는 규준에 SSD 아동이 포함되었는가 하는 것이 다. 규준 자료로 사용되기 위한 샘플은 말 또는 언어문제 이력을 지 닌 아동들을 포함해야 하는데, 이는 일반적으로 발달하는 아동을 정규분포곡선의 하단에 위치하게 하는 과식별을 피하기 위함이다 (Dodd, Holm, Hua, \& Crosbie, 2003). 표준화 연구 과정에서 UTAP 은 '정상 아동'을(Kim, 1996), KS-PAPT는 '정상발달 범주에 있는
일반아동'을 대상으로 선정하였다. APAC은 '일반아동'을 대상으 로 하였으나, '기능적 조음음운장애가 의심되는 아동'은 자료에 포 함시켰으며, 구체적으로 몇 명의 의심군 아동이 포함되었는지는 언 급하지 않았다. UTAP2는 SSD로 진단받은 아동을 전체 대상 아동 중 $10 \%$ 포함하였다. 또한, 국내의 표준화된 검사는 모두 하위그룹 당 100명 미만의 아동을 표본으로 포함하고 있다(UTAP이 30-32 명, APAC이 20-30명, KS-PAPT가 20명, UTAP2가 54-91명). 하위 그룹당 100 명 미만의 아동이 표본으로 포함될 경우 검사의 타당도 가 낮아지므로(Friberg, 2010; McCauley \& Swisher, 1984), 국내 검 사들이 포함하고 있는 제한된 표본의 수는 검사 결과 해석 시 고려 되어야 할 것이다.

\section{자음 산출 기회}

각 음소의 자음 산출 기회는 검사도구별로 차이가 있었다. 각각 의 검사가 제공하는 자음 산출 기회수에 대한 정보는 임상현장에 서 검사도구를 선정할 때 유용할 수 있다. 모든 검사는 각 단어 내 위치에서 최소 2 회의 산출이 유도되어야 한다는 기준을 부분적으 로 충족하였다. 이 2회의 산출 기회는 포괄적인 음운분석을 수행하 기 위한 바람직한 산출 기회수이자(Ingram \& Ingram, 2001; StoelGammon, 1987), 한 소리가 아동의 말소리목록에 있다고 확정 짓기 위한 일반적인 기준이다(Powell \& Miccio, 1996; Stoel-Gammon, 1985). 표준화된 검사의 제한적인 음소 산출 기회는 영어권에서 사 용되는 검사도구를 비교한 선행연구에서도 드러난 문제이다(Eisenberg \& Hitchcock, 2010; Macrae, 2017).

말소리는 같은 음소라도 어절과 음절 내 위치에 따라 다르게 발 달하므로(Kim \& Shin, 2015), 목록검사에서 말소리는 단어 내 모 든 위치에 걸쳐 평가되어야 한다. 그러나 UTAP은 어중종성과 어말 종성을 구분하지 않았으며, 말소리목록 구성에 있어서 어중종성 /ㅂ, ㄷ, ㅁ, ㅇ, 리와 어말종성 / ᄀ , ㄴ/는 평가 기회를 제공하지 않 았다. 더욱이 목표음소뿐 아니라 전체 자극단어에서도 어중종성 /비와/리/의 산출 기회를 1 회도 제공하지 않았다.

네 검사는 평가를 위한 목표음소목록에서도 차이를 보였는데, 한국어 말소리가 구어에서 사용되는 양상을 고려하지 않고 모든 음소의 산출을 엄격하게 보려는 시도에서 몇 가지 문제가 관찰되었 다. 한국어의 성문마찰음 /히는 한 단어 안의 공명음 사이에 위치 할 때 수의적인 탈락이 일어나는 음소이다(Kim \& Shin, 2015).UTAP 과 KS-PAPT는 해당 음소를 평가에 포함하였는데, UTAP의 '전화' 를 [저나]로 산출하거나, KS-PAPT의 '비행기'를 [비앵기]로 산출한 다 하더라도 오류라고 할 수 없다. 더욱이 UTAP의 '전화'는 어중종 성 /니를 보기 위한 자극단어인데, 어중종성 /ㄴ/는/ㅎㅇㅢ 수의적 
탈락에 의해 연음화된다. 결과적으로 어중초성 위치에서/ㅎ/는 일 상 발화에서 흔히 생략될 수 있으므로 단어검사를 통해 해당 음소 에 대한 목록검사를 실시하는 것은 적절하지 않으며, 해당 음소에 인접하여 선행하는 자음을 어중종성 위치에서 평가하는 것 또한 적절하지 않다.

한국어에서 어중종성 /ㄷ/는 후행하는 자음의 연쇄로 인해 조음 위치 동화와 탈락이 일어나므로 해당 위치에서는 실현되지 않는다 (Woo \& Kim, 2013). KS-PAPT는 단어 '숟가락'에서 해당 음소의 산출을 유도한다. KS-PAPT의 검사지침서 24 쪽은 해당 음소를 생 략하여 발음하여도 오조음하였다고 볼 수 없으므로 산출을 확인 하기 위해 한 번 더 모방할 필요가 있다고 명시하고 있다. 그러나 말 소리목록을 평가하는 기준은 자발적인 산출이므로(Eisenberg \& Hitchcock, 2010), 이미 자발적으로 산출하지 못한 소리를 위해 모 방 산출 기회를 제공하는 것은 목록검사를 실시하는 방법으로 타 당하지 않다.

한국어에서 유음/리는 단어 내 위치에 따라 설측음 또는 탄설 음으로 산출되는데, 어중초성 위치에서는 보통 탄설음으로 산출되 지만, 어중종성 /리에 인접하여 후행하는 경우 설측음으로 산출된 다(Choi \& Kim, 2013). APAC은 어중초성 /리를 평가하기 위한 단 어로 '올라가'를 포함하는데, 여기서 산출되는 어중초성 /리는 설 측음으로, 탄설음으로 산출되는 다른 어중초성 /리와는 구별되어 져야한다.

\section{단어의 복잡성과 말소리목록}

네 검사도구에 포함된 단어들의 평균 PMLU는 7-8로 유사한 수 준이었다. 일반적인 자발화에서 2세의 평균 PMLU가 7-8임을 고려 할 때(Ha \& Hwang, 2013), 네 검사 단어의 평균음운길이는 학령전 아동의 음운능력을 평가하기에 적절함을 알 수 있다. 네 검사는 목 표음소의 산출을 유도하기 위해 각기 다른 자극단어를 사용하였 는데, 검사에 따라 자극단어의 PMLU에 차이가 있는 것으로 나타 났다. PMLU는 음운길이를 나타냄과 동시에 단어수준의 복잡성을 나타내는 지표이다(Kim \& Shin, 2015). 따라서 이러한 PMLU 차이 는 같은 음소를 목표로 하더라도 검사마다 사용한 단어의 복잡성 에서차이가 있었음을 의미한다.

선행연구들에 의하면 복잡한 단어는 덜 복잡한 단어에 비해 덜 정확하게 산출된다(Macrae, 2013; McLeod \& Hewett, 2008; Sosa \& Stoel-Gammon, 2012). 앞서 언급하였듯이, 네 검사는 목표음소 의 산출이 유도된 자극단어의 복잡성에서 차이가 있었으며, 이러 한 차이는 실제 SSD 아동의 검사 결과에 영향을 미쳤다. 특히 앞선 연구1에서 목표단어의 PMLU가 최고 5 이상 차이나는 음소들을
살펴보면, 어두초성에서는 10 개의 음소(/ㅂ, 뻐, ㄸ, ᄀᄀ, ㄱ, 흐, ㅉ, ㅊ, ㅁ, ㄴ/) 중 1 개의 음소(/ㅎ/)를 제외한 나머지 9 개 음소에서, 어 중초성에서는 8 개의 음소(/빠, 프, ᄃ, ㅅ, ㅆ, ㅎ, ㅈ, ㅁ/) 중 1 개의 음소(/ᄃ/)를 제외한 나머지 7개 음소에서 모두 PMLU가 낮은 단 어보다 PMLU가 높은 단어에서 목표음소를 산출하지 못한 아동 의 수가 더 많았다.

말소리목록에 지니지 못한 아동 수의 차이가 큰 음소들을 살펴 보면, 특히 어두초성에서 대부분 PMLU가 가장 높은 단어를 유도 했을 때 해당 음소를 산출하지 못한 아동 수가 가장 많았다. 어두 초성 말소리목록에서 4 명 이상의 차이를 보인 8 개의 음소(, ㅋ, 人, ㅎ, ㅉ, ㅊ, ᄂ, ㄹ/) 중 6 개의 음소(/匹, ㄱ, ㅉ, ㅊ, ᄂ, ㄹ/)가 그 예인데, 해당 음소가 유도된 단어의 PMLU는 검사에 따라 최소 5 에서 최고 8까지 차이가 있었다. 이러한 결과는 단어가 포함하고 있 는 분절음의 수가 많고 복잡할 때 목표음소가 덜 정확하게 산출되 었음을 시사하며, 목록분석을 위한 목표음소의 산출은 음절길이 가 짧은, 덜 복잡한 환경에서 유도되어야 한다는 Eisenberg와 Hit$\operatorname{chcock}$ (2010)의 주장을 지지한다.

예외가 된 음소를 살펴보면, 어두초성 /히는 U-TAP과 APAC, $\mathrm{UTAP} 2$ 에서 모든 아동이 산출에 성공하였으나, PMLU가 가장 낮 은 단어인 KS-PAPT의 [휴지]에서 12 명의 아동이 해당 음소를 산 출하지 못하였다. KS-PAPT는 다른 검사의 자극단어와 달리 $\mathrm{j}$ 계열 이중모음 문맥에서 /히의 산출을 유도한다. 또한 j계 이중모음은 전설고모음이다. SSD 아동의 /ㅎ/ 산출에 영향을 미친 것이 j계 이 중모음 문맥인지 전설고모음 문맥인지는 추후 연구에서 확인해야 한다. 어두초성 / 시는 모두 PMLU가 같은 어휘에서 산출이 유도되 었는데, 산출에 성공한 아동이 가장 많은 단어는 KS-PAPT의 [수 박]이고, 나머지 검사에서는 모두 [사탕]을 목표단어로 포함한다. 산출에 영향을 미친 것이 모음문맥의 영향인지, 단어 친숙도의 영 향인지는 추후 연구에서 확인할 필요가 있다.

어중초성에서는 어두초성에서 관찰된 경향성이 비교적 적게 관 찰되었는데, 이러한 결과는 자음 연쇄의 영향을 받은 것으로 보인 다. 실제로 Table 7을 살펴보면, 모든 검사가 동일한 환경에서 산출 을 유도한 음소 외 11 개의 음소 중 가장 많은 아동이 산출에 성공 한 9 개의 음소는 자음의 연쇄 없이 모음 뒤에서 산출이 유도되었다. 이는 영어의 자음군 문맥과 마찬가지로 한국어에서 자음이 연쇄되 는 환경이 목표음소의 산출 정확도에 영향을 미칠 수 있음을 의미 하며, 자음군 문맥이 말소리목록을 구성하기 위한 산출 기회로 적 절하지 않다고 주장한 Eisenberg와 Hichcock (2010)의 주장을 지 지한다. 따라서 어중초성 위치에서 목록 검사를 시행할 때에는 자 음이 연쇄되지 않은 환경에서 목표음소의 산출이 유도되어야 할 
것이다.

어중초성 /리는 APAC에서 올바르게 산출한 아동이 가장 많은 것으로 나타났는데, 이는 다른 검사들이 모두 탄설음만을 목표로 한 것과 달리 설측음을 목표음소에 포함한 결과로 보인다. /리를 말소리목록에 지닌 아동 5 명 중 4 명의 아동은 [머리, 호랑이, 고래] 중 하나의 목표단어와 [올라가]에서 각 1 회씩 산출에 성공하였는 데, 탄설음만을 목표로 말소리목록을 작성한다면 이 대상 아동들 은/리산출에 실패한 것으로 보아야 한다.

자극단어의 차이가 말소리목록 구성의 차이로 이어진 결과는 자극단어가 목표음소의 산출에 영향을 미쳤음을 시사한다. 말소 리목록 분석의 목적은 아동이 산출하는 소리와 산출하지 못하는 소리 모두를 확인하는 것이다(Eisenberg \& Hitchcock, 2010). 따라 서 아동이 산출 가능한 소리가 특정 단어를 유도함에 따라 산출하 지 못하는 것으로 평가된다면 평가 과정에서 수집된 말샘플이 아 동의 말소리목록을 대표한다고 보기 어려우며, 중재 목표 및 우선 순위를 결정하는 데 영향을 미칠 수 있다. 국내의 표준화된 말소리 검사는 모두 목록검사로서 한계를 갖는 것으로 드러났다. 목록검 사를 실시할 때는 단어 내 위치별로 산출이 가장 쉬운 조건에서 목 표음소의 산출이 유도되어야 한다. 따라서 앞으로의 목록검사는 단어 내 위치별 음소 산출이 쉬운 조건을 고려한 자극단어들을 포 함하여 개발되어야 할 것이다.

본 연구에서는 각 검사도구에서 제공하는 음운오류패턴 분석 체계에 관해 다루지 않았으며, 대상 아동들의 샘플에 대한 관계분 석 역시 실시하지 않았다. 음운오류패턴의 분석은 좀 더 발달된 말 소리 체계에 적합하므로(Bankson et al., 2013), 음운오류패턴 분석 에 사용되는 자극은 목록검사를 위한 자극과 그 특성에서 차이를 보일지도 모른다. 음운오류패턴의 분석은 오류를 분류하고 치료 계획을 수립하는 데 있어 중요한 주제이므로, 향후 음운오류패턴 과 관련된 연구 역시 실시되어야 한다.

결론적으로 현재 임상에서 사용 가능한 말소리검사는 대상 아 동의 말소리 능력을 평가하는 단일의 수단으로 충분하지 않았다. 이러한 문제는 국내 검사들만의 문제가 아니며, 한낱말검사가 갖는 한계로 볼 수 있을 것이다. 따라서 포괄적인 음운분석을 위해 표준 화된 검사를 토대로 얻은 결과에만 의존해서는 안 되며, 단어검사 를 사용하는 것에서 오는 한계점들을 이해하고 평가에 적용해야 할 것이다. 각 검사들이 한낱말검사로서 갖는 한계에도 불구하고, 임상에서 표준화된 검사를 사용하는 이유는 현장 적용에 있어서 가장 효율적인 수단이기 때문일 것이다. 또한 장애진단을 표준화 검사 결과로만 하지는 않는다. 말소리장애도 앞서 살펴본 바와 같 이 (1) 명료도의 손상으로 의사소통이 어렵고, (2) 사회적 참여에 제
한이 있는가를 진단기준으로 설정하고 있다. 이런 기준은 '기능적 관점'에서 불이익이 있는지가 진단기준임을 보여주는 것이다. 여기 에 명료도를 비교적 일관성 있게 관찰할 수 있는 PCC 등의 지표를 검사 지표로, 전체 집단의 표준화 분포를 구하고 그 안에서 검사 대 상자의 상대적 위치(퍼센타일)를 구하여 장애 진단의 보완 장치로 표준화 검사 결과를 활용해야 한다. 아직 각각의 분석 목적에 완전 히 부합하는 검사들이 출시되지 않은 시점에서, 표준화 검사가 갖 는 한계들은 역동적 심화 검사를 통해 보완될 수 있다. 좀 더 쉬운 조건에서 음소의 산출을 유도하기 위해서는 기존의 문맥검사표를 활용할 수 있을 것이다. 반대로 좀 더 어려운 조건에서 산출을 유도 하고 음운오류패턴을 살펴보기 위한 보완책으로는 각 검사에 포함 된 문장검사를 활용할 수 있을 것이다. 역동적 심화 검사를 통한 보 충평가는 대상 아동이 지닌 말소리 문제에 대해 보다 자세하고 포 괄적인 정보를 제공할 것이며, 이는 효율적이고 효과적인 중재를 위 한 밑거름이 될 것이다.

\section{REFERENCES}

Bankson, N. W., Bernthal, J. E., \& Flipsen, P. (2013). Phonological assessment procedures. In J. E. Bernthal et al. (Eds.), Articulation and phonological disorders: speech sound disorders in children (7th ed., pp. 180-211). Boston, MA: Pearson.

Bernthal, J. E., Bankson, N. W., \& Flipsen, P. (2017). Articulation and phonological disorders: speech sound disorders in children (8th ed.). Boston, MA: Pearson.

Choi, M. S., \& Kim, S. J. (2013). Morphological influences on liquid acquisition in Korean children's spontaneous speech. Communication Sciences \& Disorders, 18(1), 76-85.

Dodd, B., Holm, A., Hua, Z., \& Crosbie, S. (2003). Phonological development: a normative study of British English-speaking children. Clinical Linguistics \& Phonetics, 17(8), 617-643.

Eisenberg, S. L., \& Hitchcock, E. R. (2010). Using standardized tests to inventory consonant and vowel production: a comparison of 11 tests of articulation and phonology. Language, Speech, and Hearing Services in Schools, 41(4), 488-503.

Elbert, M., \& Gierut, J. A. (1986). Handbook of clinical phonology: approaches to assessment and treatment. San Diego, CA: College-Hill Press.

Friberg, J. C. (2010). Considerations for test selection: how do validity and reliability impact diagnostic decisions? Child Language Teaching and Therapy, 26(1), 77-92. 
Ha, J. W., Kim, S. J., Kim, Y. T., \& Shin, M. (2019). Developmental analysis in Korean children's speech production using percentage of consonants correct and whole-word measurements. Communication Sciences \& Disorders, 24(2), 469-477.

Ha, S., \& Hwang, J. (2013). Speech measures from phonological analyses of spontaneous conversations in children between 18-47 months of age. Communication Sciences \& Disorders, 18(4), 425-434.

Ingram, D. (2002). The measurement of whole-word productions. Journal of Child Language, 29(4), 713-733.

Ingram, D., \& Ingram, K. D. (2001). A whole-word approach to phonological analysis and intervention. Language, Speech, and Hearing Services in Schools, 32(4), 271-283.

Khan, L. M. (2002). The sixth view: assessing preschoolers' articulation and phonology from the trenches. American Journal of Speech-Language Pathology, 11(3), 250-254.

Kim, Ha, Kim, \& Shin (in press). Urimal Test of Articulation and Phonology 2nd edition (UTAP2). Manuscript in preparation.

Kim, M. J. (2006). The phonological error patterns of preschool children in the 'Korean Test of Articulation for Children'. Korean Journal of Communication \& Disorders, 11(2), 17-31.

Kim, M. J., Pae, S., \& Park, C. I. (2007). Assessment of Phonology and Articulation for Children (APAC). Incheon: Human Brain Research \& Consulting Co.

Kim, S. J. (2006). Development of a Korean assessment model for the articulation and phonological disorders. Korean Journal of Communication \& Disorders, 11(2), 32-55.

Kim, S. J. (2010). Syllable-final consonant error patterns of children with phonological disorders. Korean Journal of Communication \& Disorders, 15(4), 549-560.

Kim, S. J. (2014). Phonological error patterns of conversational speech produced by 2-and 4-year-old children. Communication Sciences \& Disorders, 19(3), 361-370.

Kim, S. J., \& Shin, J. Y. (2015). Speech sound disorders. Seoul: Sigmapress.

Kim, Y. T. (1996). A study of percentage of correct consonant in 2-6 years through picture articulation test. Korean Journal of Communication \& Disorders, 1, 7-33.

Kim, Y. T., \& Shin, M. J. (2004). Urimal Test of Articulation and Phonology (U-TAP). Seoul: Hakjisa.

Kirk, C., \& Vigeland, L. (2015). Content coverage of single-word tests used to assess common phonological error patterns. Language, Speech, and Hear- ing Services in Schools, 46(1), 14-29.

Lee, E. J., Han, J. S., \& Sim, H. S. (2004). The effects of the phonetic complexity on the disfluencies and the articulation errors of people who stutter. Korean Journal of Communication \& Disorders, 9(3), 139-156.

Macrae, T. (2013). Lexical and child-related factors in word variability and accuracy in infants. Clinical Linguistics \& Phonetics, 27(6-7), 497-507.

Macrae, T. (2017). Stimulus characteristics of single-word tests of children's speech sound production. Language, Speech, and Hearing Services in Schools, 48(4), 219-233.

McCauley, R. J., \& Swisher, L. (1984). Psychometric review of language and articulation tests for preschool children. Journal of Speech and Hearing Disorders, 49(1), 34-42.

McLeod, S., \& Baker, E. (2014). Speech-language pathologists' practices regarding assessment, analysis, target selection, intervention, and service delivery for children with speech sound disorders. Clinical Linguistics \& Phonetics, 28(7-8), 508-531.

McLeod, S., \& Hewett, S. R. (2008). Variability in the production of words containing consonant clusters by typical 2-and 3-year-old children. Folia Phoniatrica et Logopaedica, 60(4), 163-172.

Miccio, A. W. (2002). Clinical problem solving: assessment of phonological disorders. American Journal of Speech-Language Pathology, 11(3), 221-229.

Olsen, M. W. (2010). Investigation of speech samples from typically developing preschool age children: a comparison of single words and imitated sentences elicited with the PABA-E (Master's thesis). Portland State University, Portland, OR, USA.

Park, H. J., \& Shin, H. J. (2003). A study on effect of tests for assessment of phonological process in children with phonological disorders. Journal of Speech \& Hearing Disorders, 12(2), 175-188.

Powell, T. W., \& Miccio, A. W. (1996). Stimulability: a useful clinical tool. Journal of Communication Disorders, 29(4), 237-253.

Seok, D., Park, S., Shin, H., \& Park, H. (2008). Korean Standard Picture of Articulation and Phonological Test (KS-PAPT). Seoul: Hakjisa.

Shin, J. (2008). Bi-phoneme frequency of Korean based on the analysis of spontaneous speech data. Korean Journal of Communication \& Disorders, 13(3), 477-502.

Skahan, S. M., Watson, M., \& Lof, G. L. (2007). Speech-language pathologists' assessment practices for children with suspected speech sound disorders: results of a national survey. American Journal of Speech-Language Pathology, 16(3), 246-259.

Sosa, A. V., \& Stoel-Gammon, C. (2012). Lexical and phonological effects in 


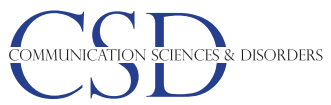

early word production. Journal of Speech, Language, and Hearing Research, 55(2), 596-608.

Stoel-Gammon, C. (1985). Phonetic inventories, 15-24 months: a longitudinal study. Journal of Speech, Language, and Hearing Research, 28(4), 505512.

Stoel-Gammon, C. (1987). Phonological skills of 2-year-olds. Language, Speech, and Hearing Services in Schools, 18(4), 323-329.
말소리검사 단어 특성 및 말소리장애 아동 검사 결과의 비교 - 이루다 외

Woo, H., \& Kim, S. (2013). Coda sounds acquisition at word medial position in three and four year old children's spontaneous speech. Phonetics and Speech Sciences, 5(3), 73-81.

Yoon, M. S., Kim, J. M., \& Kim, S. J. (2013). Phonological whole-word measures of spontaneous speech in children two to four years of age. Journal of Speech-Language \& Hearing Disorders, 22(4), 69-85. 
Appendix 1. Information of participants

\begin{tabular}{|c|c|c|c|c|c|c|}
\hline \multirow{2}{*}{ No. } & \multirow{2}{*}{$\begin{array}{c}\text { Age } \\
\text { (yr;mo) }\end{array}$} & \multirow{2}{*}{ Gender } & \multicolumn{4}{|c|}{ Total PCC/Target PCC (SD) } \\
\hline & & & UTAP & APAC & KS-PAPT & UTAP2 \\
\hline 1 & $5 ; 3$ & Boy & $85.06 / 90.70(<-2$ SD) & 84.38/82.86 (-2 SD to -1 SD) & $85.23 / 86.00$ (<-2 SD) & $87.23 / 87.50$ (-2 SD to -1 SD) \\
\hline 2 & $3 ; 9$ & Boy & $79.31 / 81.40$ (-2 SD to -1 SD) & 72.92/77.14 (-2 SD to -1 SD) & $72.73 / 74.00$ (<-2 SD) & 77.66/77.08 (-1 SD to 0 SD) \\
\hline 3 & $6 ; 5$ & Girl & $49.43 / 53.49(<-2$ SD) & $46.88 / 47.14(<-2$ SD) & $51.14 / 48.00(<-2$ SD) & $54.26 / 60.42(<-2$ SD) \\
\hline 4 & $6 ; 0$ & Girl & $81.61 / 83.72$ (<-2 SD) & $85.42 / 87.14$ (<-2 SD) & $82.95 / 80.00$ (<-2 SD) & $86.17 / 89.58$ (<-2 SD) \\
\hline 5 & $5 ; 1$ & Boy & $86.21 / 86.05$ (<-2 SD) & 87.50/88.57 (-1 SD to 0 SD) & $87.50 / 90.00$ (<-2 SD) & $86.17 / 85.42$ (-2 SD to -1 SD) \\
\hline 6 & $4 ; 0$ & Boy & 49.43/60.47 (<-2 SD) & $52.08 / 50.00(<-2$ SD) & $38.64 / 32.00(<-2$ SD) & $46.81 / 43.75(<-2$ SD) \\
\hline 7 & $3 ; 3$ & Girl & $41.38 / 44.19(<-2$ SD) & $42.71 / 47.14(<-2$ SD) & $43.18 / 48.00(<-2$ SD) & $39.36 / 43.75$ (<-2 SD) \\
\hline 8 & $5 ; 7$ & Boy & 95.40/93.02 (-2 SD to - 1 SD) & $89.58 / 90.00$ (-2 SD to -1 SD) & $88.64 / 84.00(<-2$ SD) & $87.23 / 87.5(<-2$ SD) \\
\hline 9 & 3.7 & Girl & $34.48 / 30.23(<-2$ SD) & $37.50 / 37.14$ (<-2 SD) & $27.27 / 28.00(<-2 \mathrm{SD})$ & $38.30 / 35.42$ (<-2 SD) \\
\hline 10 & $4 ; 8$ & Boy & $65.52 / 72.09$ (<-2 SD) & $62.50 / 65.71$ (<-2 SD) & $60.23 / 58.00$ (<-2 SD) & $62.77 / 66.67$ (<-2 SD) \\
\hline 11 & $4 ; 5$ & Boy & $67.82 / 74.42$ (<-2 SD) & $72.92 / 74.29$ (<-2 SD) & $75.00 / 74.00(<-2$ SD) & 72.34/79.17 (-2 SD to -1 SD) \\
\hline 12 & $3 ; 6$ & Girl & 64.37/69.77 (<-2 SD) & $64.58 / 65.71$ (<-2 SD) & $65.91 / 74.00(<-2$ SD) & $65.96 / 75.00$ (-2 SD to -1 SD) \\
\hline 13 & $5 ; 5$ & Girl & $56.32 / 51.16$ (<-2 SD) & $57.29 / 67.14$ (<-2 SD) & $57.95 / 62.00(<-2$ SD) & $55.32 / 58.33$ (<-2 SD) \\
\hline 14 & $5 ; 1$ & Boy & 73.56/79.07 (<-2 SD) & 73.96/72.86 (<-2 SD) & $73.86 / 78.00(<-2$ SD) & $71.28 / 68.75$ (<-2 SD) \\
\hline 15 & $4 ; 3$ & Boy & 79.31/79.07 (<-2 SD) & $79.17 / 80.00$ (-2 SD to -1 SD) & $75.00 / 76.00$ (<-2 SD) & 79.79/83.33 (-2 SD to -1 SD) \\
\hline
\end{tabular}

Total PCC = percentage of consonants correct of whole words; Target PCC = percentage of consonants correct of target phonemes for scoring; UTAP=Urimal-Test of Articulation and Phonology (Kim \& Shin, 2004); APAC=Assessment of Phonology and Articulation for Children (Kim, Pae, \& Park, 2007); KS-PAPT = Korean Standard Picture of Articulation and Phonological Test (Seok, Park, Shin, \& Park, 2008); UTAP2=Urimal-Test of Articulation and Phonology 2nd edition (Kim, Ha, Kim, \& Shin, in press). 


\section{국문초록}

\section{말소리검사 단어 특성 및 말소리장애 아동 검사 결과의 비교}

이루다 $\cdot$ 김수진

'밤비니언어인지발달상담센터, ${ }^{2}$ 나사렛대학교 언어치료학과

배경 및 목적: 본 연구에서는 국내에서 표준화된 네 개의 말소리검사에 포함된 자극단어 특성을 비교하고, 말소리장애 아동에게 네 검 사를 모두 실시했을 때 검사 결과에서 어떠한 차이를 보이는지 살펴보았다. 방법: 연구1에서는 말소리장애 아동 15 명을 대상으로 네 검 사를 모두 실시한 후, 검사에 따라 대상 아동들의 전체 단어 및 규준 자음정확도, 규준 구간, 말소리목록에 어떠한 차이가 있는지 비교 하였다. 연구 2 에서는 각각의 검사가 제공하는 자음산출 기회수를 단어 내 위치에 걸쳐 비교하고, 자극단어들의 음운구조 복잡성을 비 교하였으며, 연구 1 의 대상 아동들의 말소리목록에 어떤 차이가 있는지 살펴보았다. 결과: 연구 1 에서 네 검사의 자음정확도는 모두 높은 상관을 보였으나, 대상 아동들이 속한 규준 구간은 검사에 따라 차이가 있었다. 연구2에서 자음산출 기회수와 자극단어의 복잡성은 검 사별로 차이가 있었으며, 복잡성에 따라 대상 아동들의 말소리목록에도 차이가 있었다. 논의 및 결론: 자극단어 특성을 비교한 결과는 임상현장에서 대상 아동 수준 및 평가 목적에 적절한 검사를 선정하는 데 활용될 수 있을 것이다. 본 연구는 현재 국내의 검사들이 아 동의 말소리목록을 구성하는 데 갖는 한계를 언급하였으며, 임상가들에게 하여금 국내의 말소리검사가 갖는 한계를 이해하고 보충 평 가를 실시할 것에 대해 제안한다.

핵심어: 말소리장애, 표준화 검사, 자극단어, 말소리목록

\section{참고문헌}

김민정(2006). '아동용 조음검사'에 나타난 취학 전 아동의 음운 오류패턴. 언어청각장애연구, 11(2), 17-31.

김민정, 배소영, 박창일(2007). 아동용 발음평가(APAC). 인천: 휴브알앤씨.

김수진(2006). 조음음운장애 진단 및 평가에 관한 질적연구: 진단모형정립을 위한 기초 연구. 언어청각장애연구, 11(2), 32-55.

김수진(2010). 기능적 조음음운장애 아동의 종성 음운변동 분석. 언어청각장애연구, 15(4), 549-560.

김수진(2014). 자발화에 나타나는 발달적 음운오류패턴. Communication Sciences \& Disorders, 19(3), 361-370.

김수진, 신지영(2015). 말소리장애. 서울: 시그마프레스.

김영태(1996). 그림자음검사를 이용한 취학전 아동의 자음정확도 연구. 말.언어장애연구, 1, 7-33.

김영태, 신문자(2004). 우리말조음-음운평가(U-TAP). 서울: 학지사.

박희정, 신혜정(2003). 조음검사 도구에 따른 음운장애아의 음운변동률차이 분석. 언어치료연구, 12(2), 175-188.

석동일, 박상희, 신혜정, 박희정(2008). 한국어표준그림 조음음운검사(KS-PAPT). 서울: 학지사.

신지영(2008). 성인 자유 발화자료 분석을 바탕으로 한 한국어의 음소 전이 빈도. 언어청각장애연구, 13(3), 477-502.

우혜경, 김수진(2013). 자발화에 나타난 3-4세 아동의 어중종성 습득. 말소리와 음성과학, 5(3), 73-81.

윤미선, 김정미, 김수진(2013). 자발화 문맥에서의 단어단위 음운 평가. 언어치료연구, 22(4), 69-85.

이은주, 한진순, 심현섭(2004). 조음복잡성이 비유창성과 조음오류에 미치는 영향. 언어청각장애연구, 9(3), 139-156.

최민실, 김수진(2013). 자발화에 나타난 3-4세 아동의 형태소 유형별 유음 발달 특성. Communication Sciences \& Disorders, 18(1), 76-85.

하승희, 황진경(2013). 18-47개월 아동의 자발화 분석에 기초한 말소리 측정치에 관한 연구. Communication Sciences \& Disorders, 18(4), 425-434. 하지완, 김수진, 김영태, 신문자(2019). 자음정확도와 단어단위 음운지표를 이용한 일반아동의 말소리 산출능력에 대한 발달 연구. Communication

Sciences \& Disorders, 24(2), 469-477.

\section{ORCID}

이루다(제1저자, https://orcid.org/0000-0002-0866-3226); 김수진(교신저자, https://orcid.org/0000-0002-9354-8504) 